\title{
Association between the HLA-G*0105N polymorphism and recurrent abortion in women
}

\author{
Z. Hajifathaliya ${ }^{1}$, R. Najafipour ${ }^{2}, \underline{\text { MH. Modarressi }}{ }^{1}$, Sh. Savad ${ }^{1}$, Z. Rashvand ${ }^{2}$
}

\author{
${ }^{1}$ Department of Medical Genetics, Tehran University of Medical Sciences, Tehran, Iran \\ ${ }^{2}$ Cellular and Molecular Research Center, Qazvin University of Medical Sciences, Qazvin, Iran \\ Corresponding Address: Mohammad Hossein Modarressi, Department of Medical Genetics, Tehran University of Medical \\ Sciences, Tehran, Iran \\ Tel: +98-912-3385292, Email: modaresi@tums.as.ir \\ Received: 31 Dec 2016; Accepted: 23 Feb 2017
}

粼 Abstract

Background: In human pregnancies HLA-G (Human leukocyte antigens G) is supposed that play a main role in implantation. It is expressed on trophoblast cells that invades during pregnancy to the uterus decidua and is introduced to induce maternal tolerance immunologically against the fetus.

Objective: The aim of this study was to find association between the HLA-G*0105N polymorphism and recurrent abortion in women.

Methods: This case-control study was conducted on two groups of 108 women with history recurrent abortion (RSA) as a case group or without history RSA as a control group in Cellular and Molecular Research Center, Qazvin University of Medical Sciences in 2015. The frequency of null allele of HLA-G*0105N was studied in two groups by PCR-RFLP method. Allele and genotype frequencies of two group were compared using Hardy-Weinberg equilibrium and Chi-square test. Findings: In case group, 54 (50\%) and 17 (15.7\%) were heterozygous and homozygous respectively for HLA-G*0105N polymorphism. In control group, only 9 (8\%) was homozygous for HLA-G*0105N polymorphism. But there was no significant difference between case and control on HLA-G*0105N allele with RSA ( $\mathrm{P}=0.1004)$.

Conclusion: As the results, there was no significant association between HLA-G*0105N poly morphism and RSA. Thus, it seems that this HLA-G*0105N polymorphism may effective in relation with other genes or polymorphisms in RSA.

Keywords: HLA-G*0105N, Polymorphism, Recurrent spontaneous abortion

Citation: Hajifathaliya Z, Najafipour R, Modarressi MH, Savad Sh, Rashvand Z. Association between the HLA-G*0105N polymorphism and recurrent abortion in women. J Qazvin Univ Med Sci 2018; 21 (6): 30-37. 


\title{
بررسى ارتباط يلىمورفيسم HLA-G*0105N با سقط مكرر در زنان داراى سابقه سقط مكرر
}

\author{
زينب حاجى فتحعليا'، دكتر رضا نجفى يور '، دكتر محمد حسين مدر سي '، دكتر شهرام سواد'، زهرا رشوند'
}

اكروه رزنتيك يزشكى دانشكاه علوم يزشكى تهران، تهران، ايران

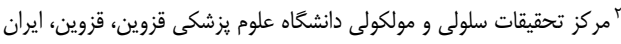

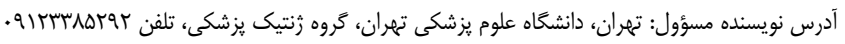
تاريخ دريافت:

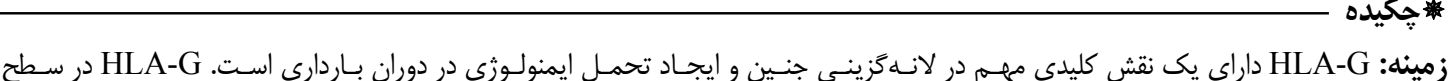

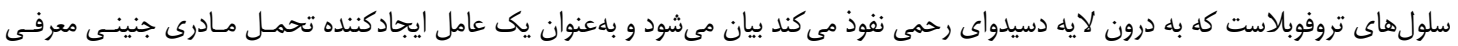

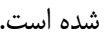

هدف: اين مطالعه به منظور بررسى ارتباط يلىمورفيسم HLA-G*0105N با سقط مكرر در زنان داراى سابقه سقط مكرر انجام شد.

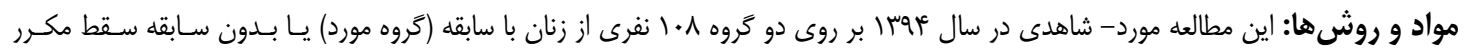

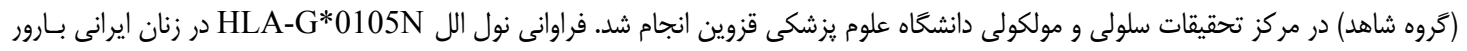

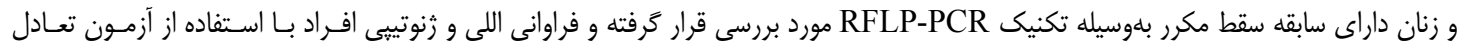

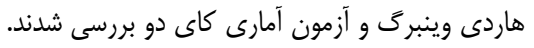

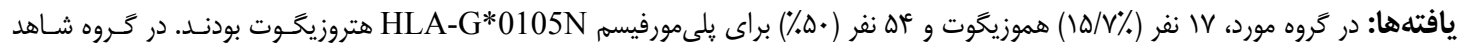

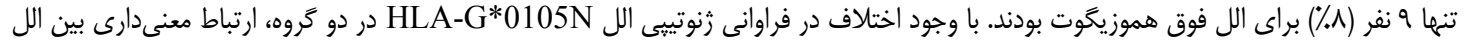

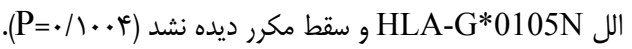

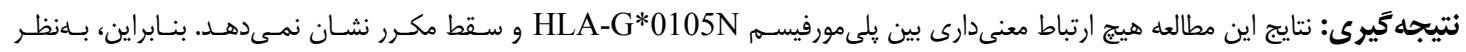

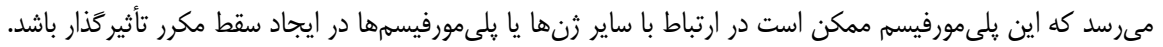

كليدوازهها: HLA-G*0105N، يلى مورفيسم، سقط مكرر

(2) مقدمه:

يكى از سؤالات اساسـى در بـاردارى ايـن اسـت كـهـ

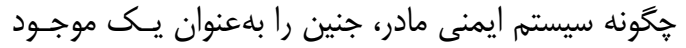

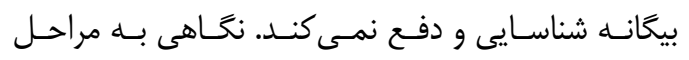

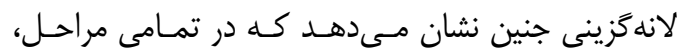
سيستم ايمنى در يذيرش جنين توسط مادر نقـش مهمى جلى دارد و مكانيسمهاى خاصسى وجـود دارد كـهـ از جنـين در

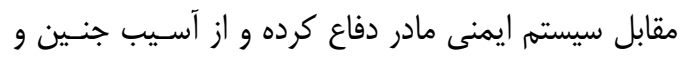

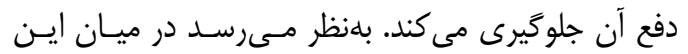

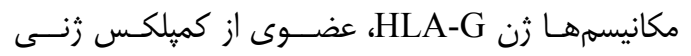

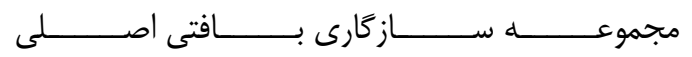
(Human Major Histocompatibility Complex, MHC)
سقط مكرر يكى از معضلات امر سلامت و بحرانهاى

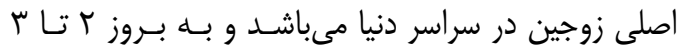
سقط يا بيشتر قبل از نيمه اول باردارى اطلاق مى شود..(') تخمين زده مىشود كه ب درصد زنان در سن بارورى دهار

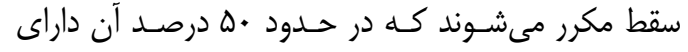
علت مشـخص نمسىباشـند و سـقط ايـديوياتيك ناميـده

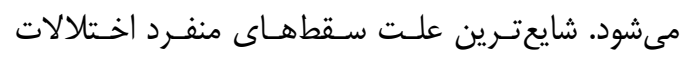
زنتيكى مىباشد در حالى كه شايعترين دليل سـقط مكــرر علل ايمنولوزيك بهحساب مىآيد. بنابراين درصد عمدهاى از سقطهاى ايديوياتيك بهعلت عملكـــد معيـوب سيستـم

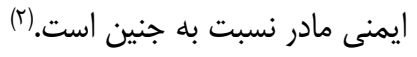


ايزوفرمهاى HLA-G1, G5, G4 كه داراى دامين 20 اند

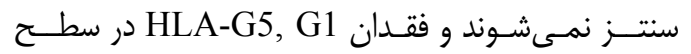

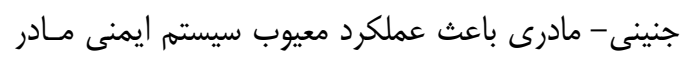

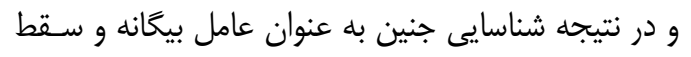

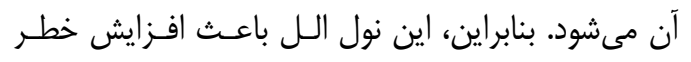

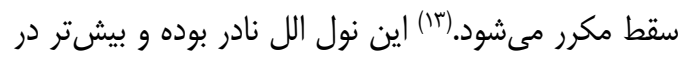

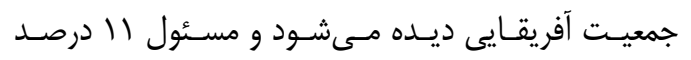

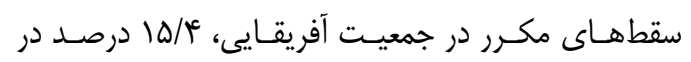

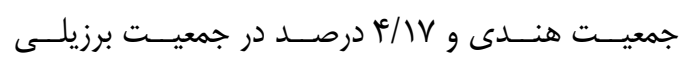

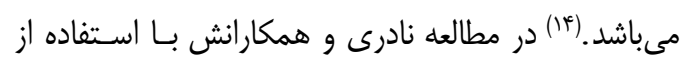

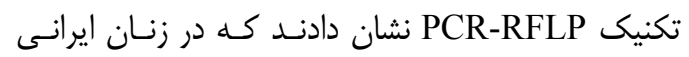

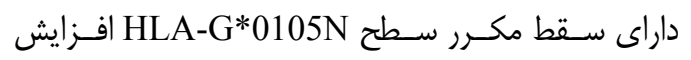

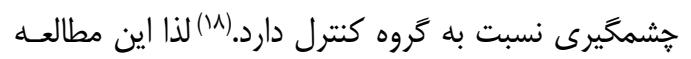

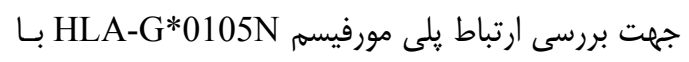
سقط مكرر در زنان داراى سابقه سقط مكرر انجام شد.

\section{مواد و روشها:}

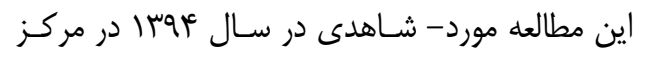

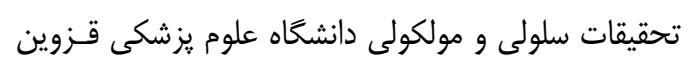

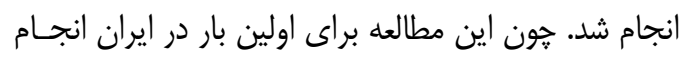

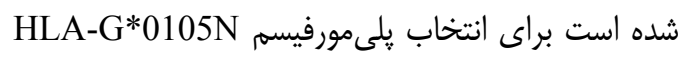

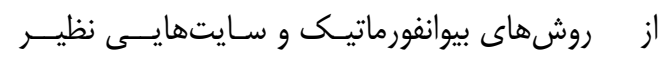
Ensembel وNCBI

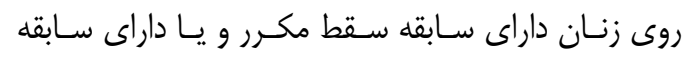
شكست IVF كه در سن بارورى (ها تا •ه سال) بودند و

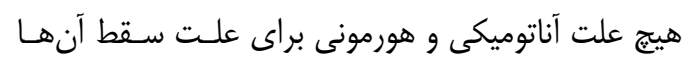

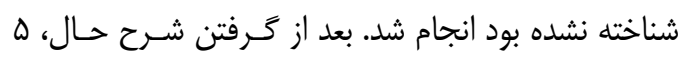

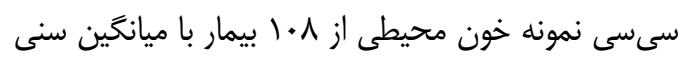

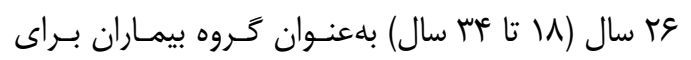

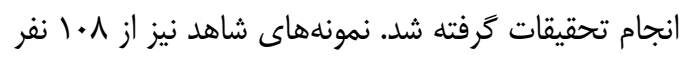

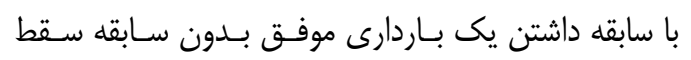

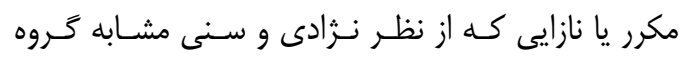

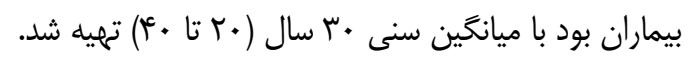

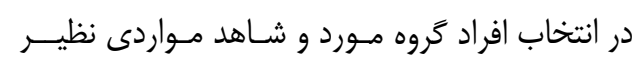

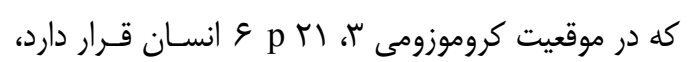
مهمترين نقش را ايفا مى كند.(r) داراى V ايزوفرم مى باشد كـه أ تـاى آنهـا

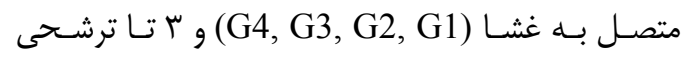
(G7, G6, G5) در بافتهاى مختلفى قابل شناسـيى مسىباشـد

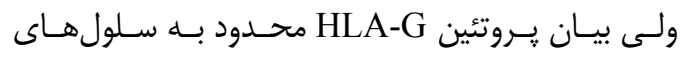

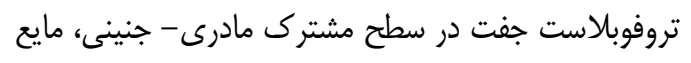

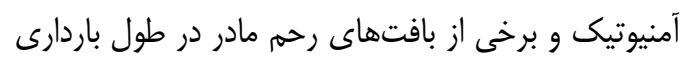

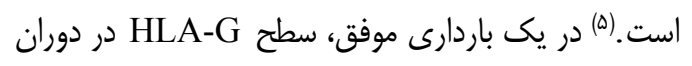

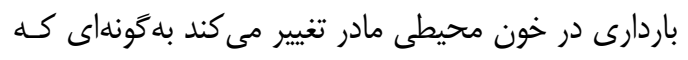

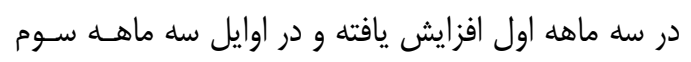

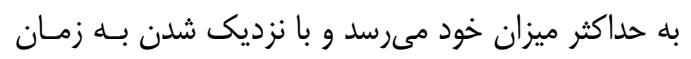

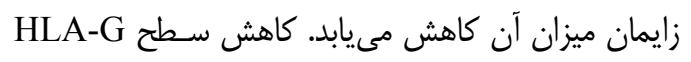

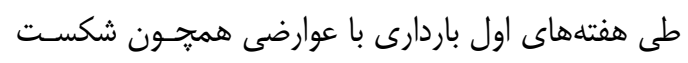

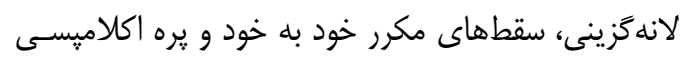

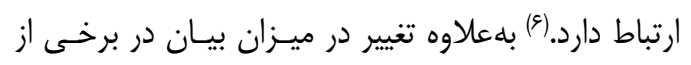

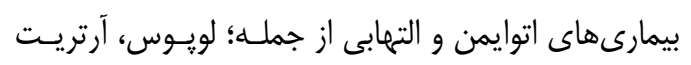

$$
\text { روماتوئيد ديده شده است. (v) }
$$

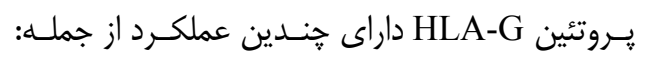
() جلوكيرى از فعاليت سلول هاى سيتوتوكسيك دسيدواى

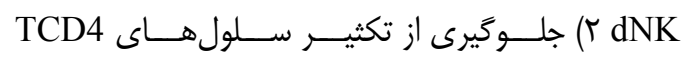

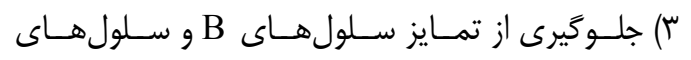

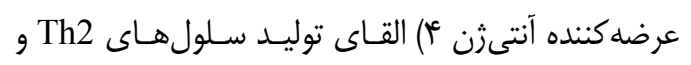
ه IL10

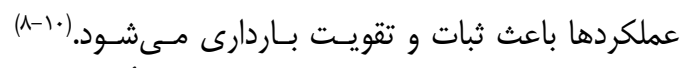
HLA-G

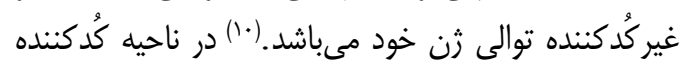

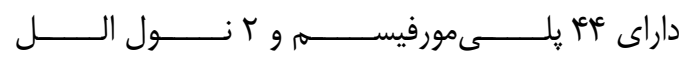
(III. HLA-G*0105, HLA-G*0103 نول الل HLA-G*0105 بهعلت حذف اسـيد آمينـهـ سيتوزين در كدون • سا اخزون س، ايجاد يك جهش تغييـر

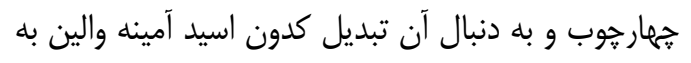

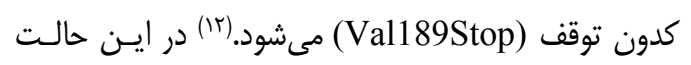




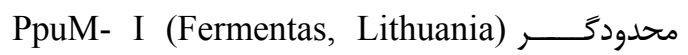

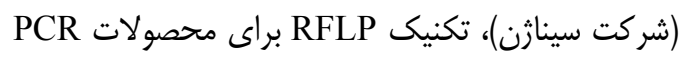

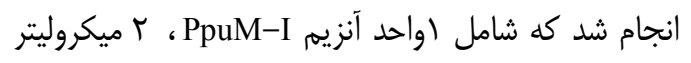

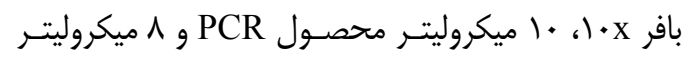

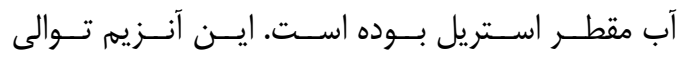

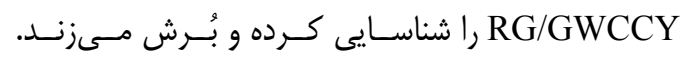

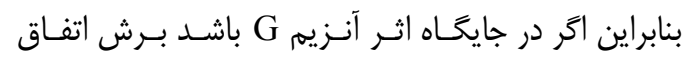

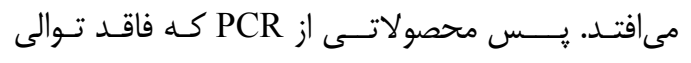

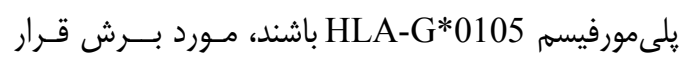

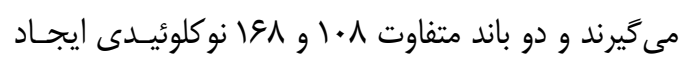

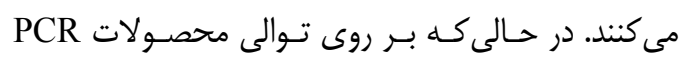

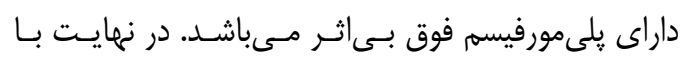

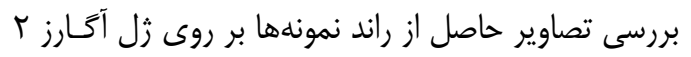

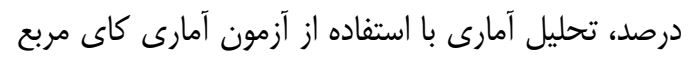

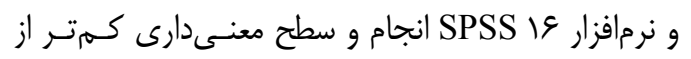

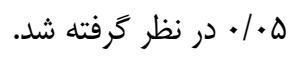

*افته ها: نتايج الكتروفورز محصولات PCR و RFLP هر فـرد

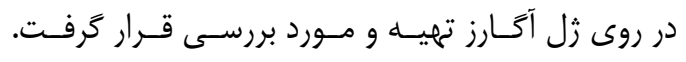
Ladder DNA

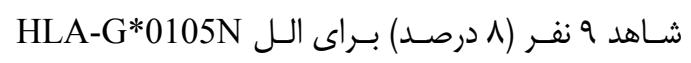
هموزيخوت بودند اين در حالى است كه در گَروه بيمـاران

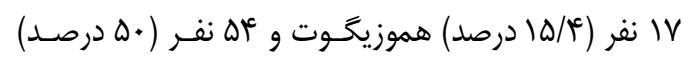

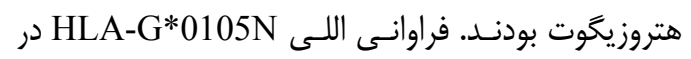

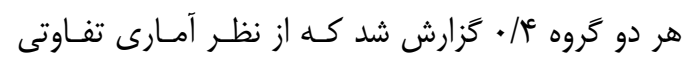

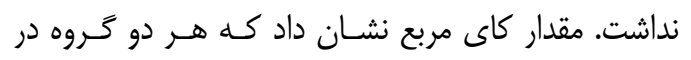

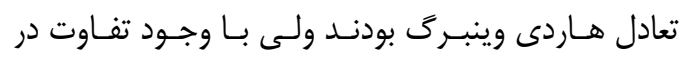

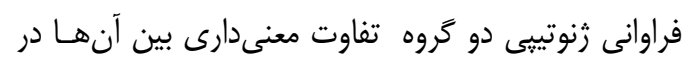

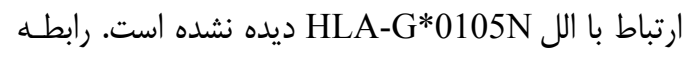
معنادارى بين وجود الل HLA-G*0105N با سقط مكرر

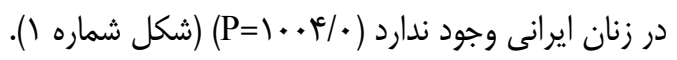

تعداد فرزند زنده و نمايه توده بــنى و ... مـدنظر نبـوده و

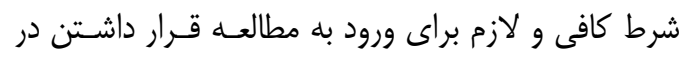
سن بارورى و داشتن سابقه سقط مكرر بوده اسـت. البتـه لـا

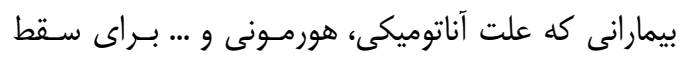
آنها تشخيص داده شده بود وارد مطالعـه نشــندي. زنوميكى هر دو گروه براساس دستورالعمل كيت استخراج شركت سينازن از خون محيطى افراد

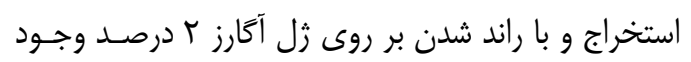
DNA در نمونههاى استخراج شده تأييد شد.

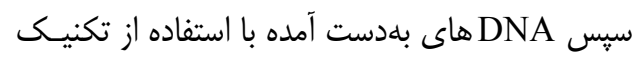
تكثير يافتنـد (Polymerase Chain Reaction, PCR)

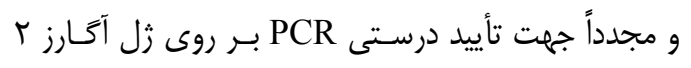

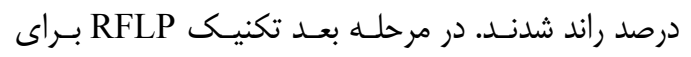

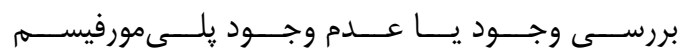

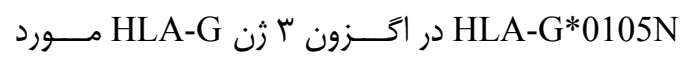

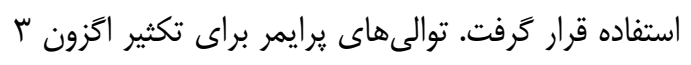

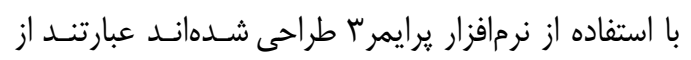
و Forward:5 -CACACCCTCCAGTGGATGAT-3 .Reverse: $5{ }^{`}$-GGTACCCGCGCGCTGCAGCA-3 ساخت يرايمرها توسط شركت سـينازن صـورت كرفت و سيس واكنش PCR در دستخاه Flexy cycle PCR بـا

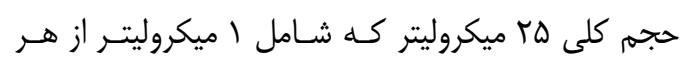
برايمر، ه/ • ميكروليتراز محصـول PCR

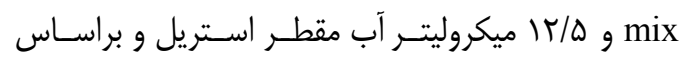

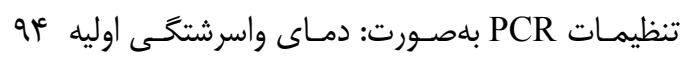

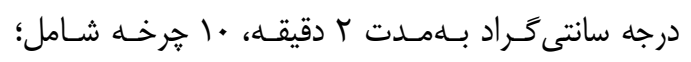

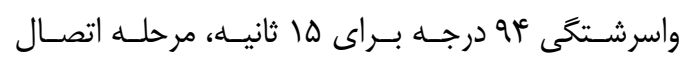

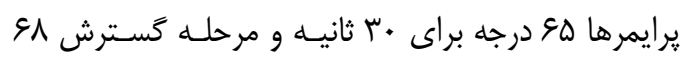

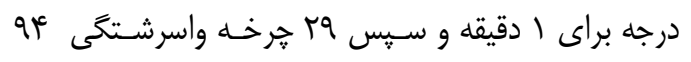

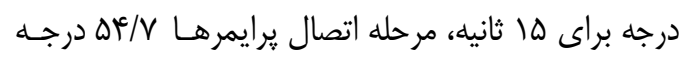

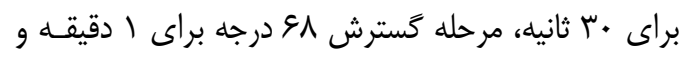
در نهايت ا دور گسترش نهايى ك V درجه سانتى

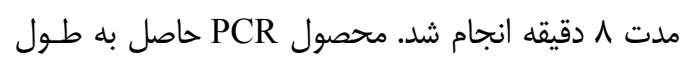

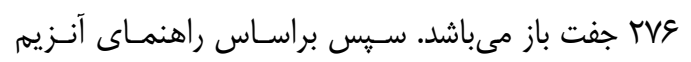


با ساير ثنهاى دخيل در سقط و يلـىورفيك ناش HLA-G

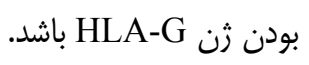

زيدى و همكارانش در بررسى سطح سرمى sHLA-G

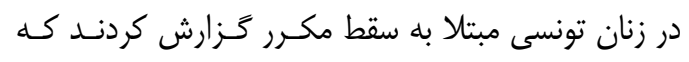

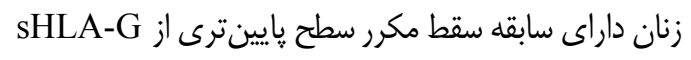

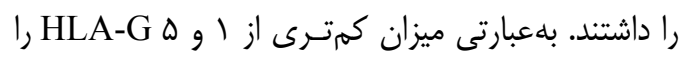

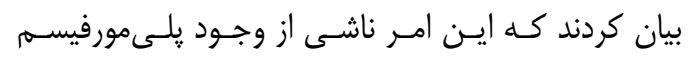

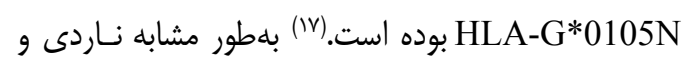
همكارانش در مطالعهاى با استفاده از تكنيك PCR-RFLP

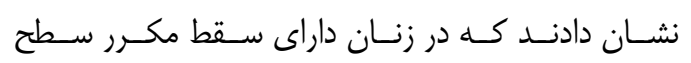
كLA-G*0105N

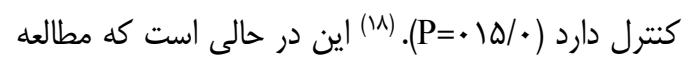

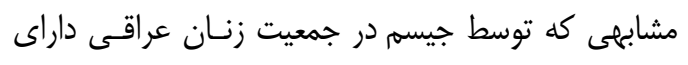

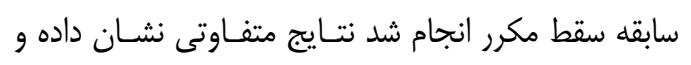

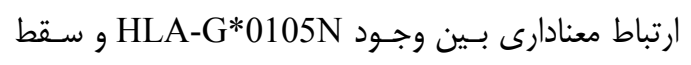

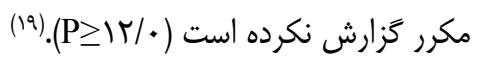

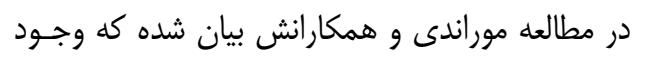

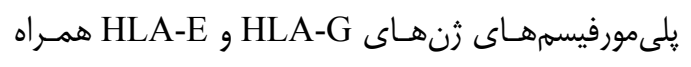

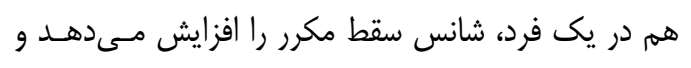

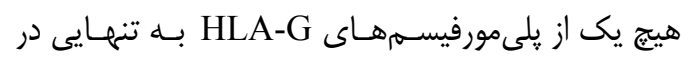

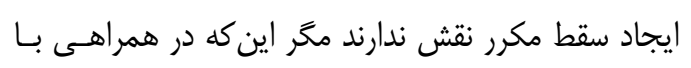

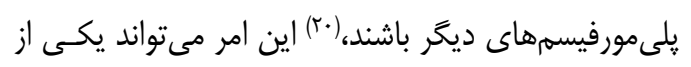

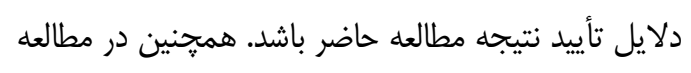

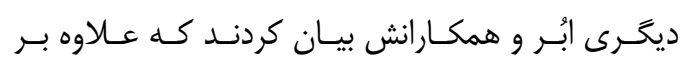

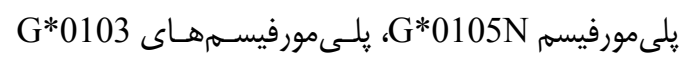

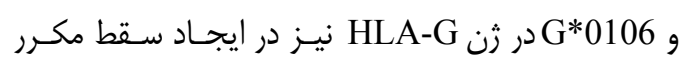

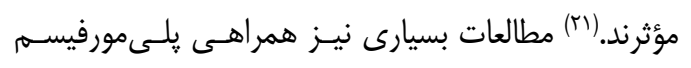

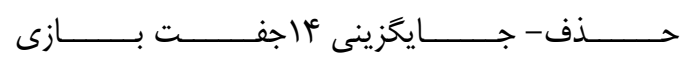

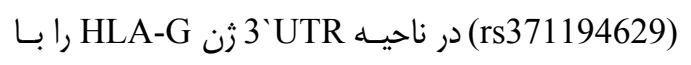
سقط مكرر نشان دادهاند. (Tr-Tr)

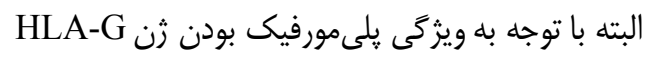

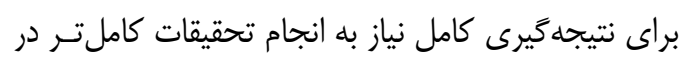

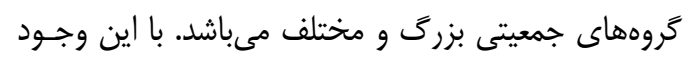

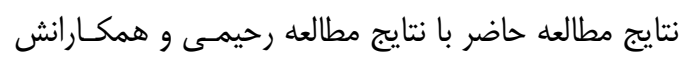

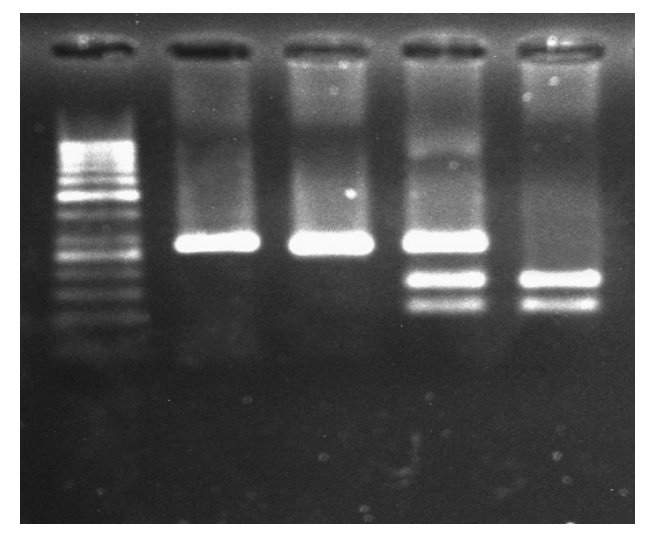

شكل ا - قطعه تكثير يافته اتزون "ا، محصول PCR و

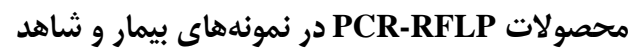

ه.DNA ladder :MW

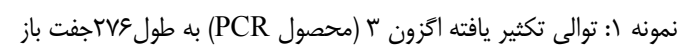

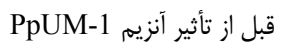

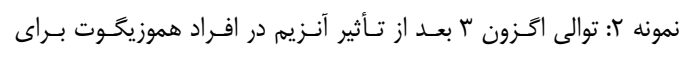

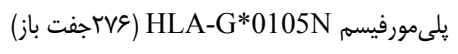

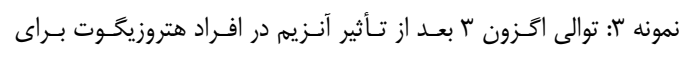

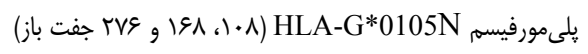

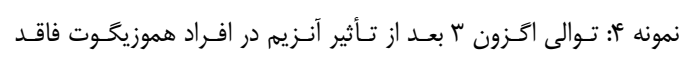

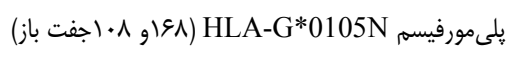

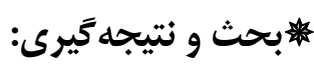

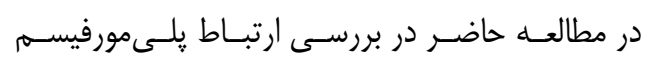

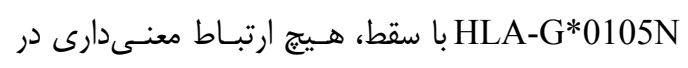

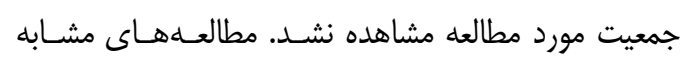

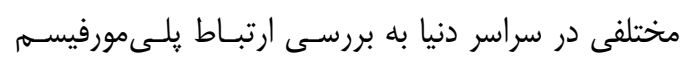

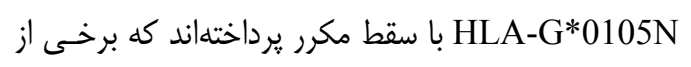

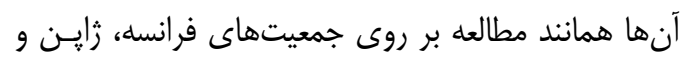

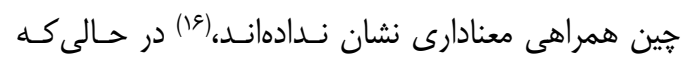

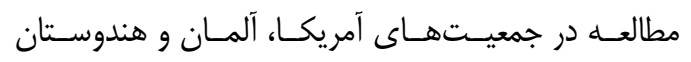

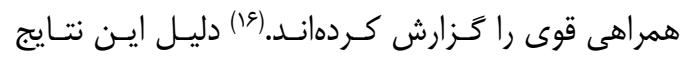

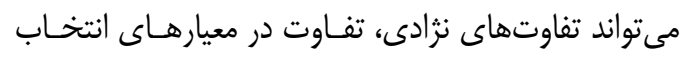

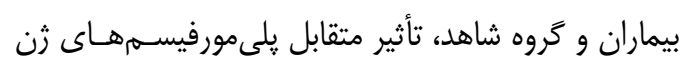

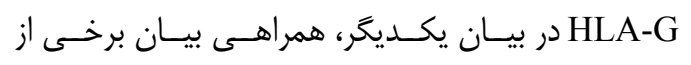

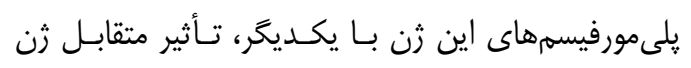


prediction. Adv Pharm Bull 2013; 3(2): 4436. doi: 10.5681/apb.2013.072.

4. Donadi EA, Castelli EC, Arnaiz-Villena A, Roger M, Rey D, Moreau P. Implications of the polymorphism of HLA-G on its function, regulation, evolution and disease association. Cell Mol Life Sci 2011; 68(3): 369-95. doi: 10.1007/s00018-010-0580-7.

5. Rizzo R, Vercammen M, van de Velde H, Horn PA, Rebmann V. The importance of HLA-G expression in embryos, trophoblast cells, and embryonic stem cells. Cell Mol Life Sci 2011; 68(3): 341-52. doi: 10.1007/ s00018-010-0578-1.

6. González A, Rebmann V, LeMaoult J, Horn PA, Carosella ED, Alegre E. The immunosuppressive molecule HLA-G and its clinical implications. Crit Rev Clin Lab Sci 2012; 49(3): 63-84. doi: 10.3109/10408363. 2012.677947.

7. Rizzo R, Bortolotti D, Baricordi OR, Fainardi E. New insights into HLA-G and inflammatory diseases. Inflamm Allergy Drug Targets 2012; 11(6): 448-63. doi: 10. 2174/187152812803590037.

8. Le Page ME, Goodridge JP, John E, Christiansen FT, Witt CS. Response to comment on "Killer Ig-like receptor 2DL4 does not mediate NK cell IFN-gamma responses to soluble HLA-G preparations. J Immunol 2014; 192(9): 4003-4. doi: 10.4049/ jimmunol.1400492.

9. Gregori S, Tomasoni D, Pacciani V, Scirpoli M, Battaglia M, Magnani CF, et al. Differentiation of type1 $\mathrm{T}$ regulatory cells (Tr1) by tolerogenic DC-10 requires the IL10-dependent ILT4/HLA-G pathway. Blood 2010; 116(6): 935-44. doi: 10.1182/blood2009-07-234872.

10. Catamo E, Addobbati C, Segat L, Sotero Fragoso T, Tavares Dantas A, de Ataide

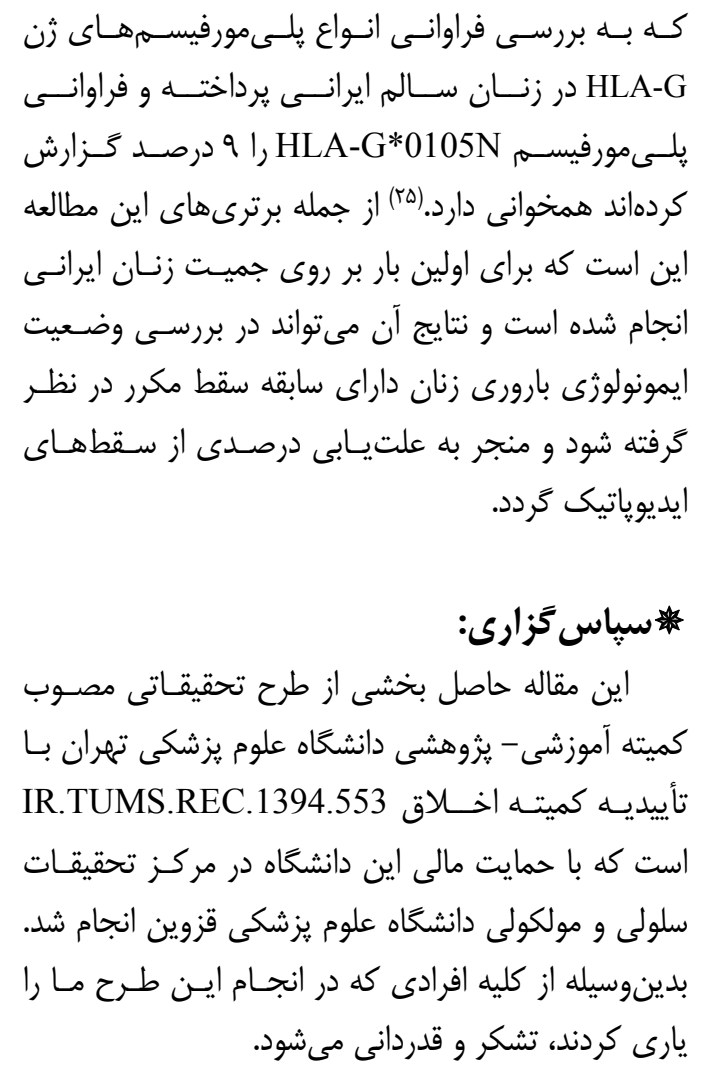

1 .Berger DS, Hogge WA, Barmada MM, Ferrell RE. Comprehensive analysis of HLAG: implications for recurrents pontaneous abortion. Reprod Sci 2010; 17(4): 331-8. doi: 10.1177/1933719109356802.

2. Akhter A, Faridi RM, Das V, Pandey A, Naik S, Agrawal S. In vitro up-regulation of HLA-G using dexamethasone and hydrocortisone in first-trimester trophoblast cells of women experiencing recurrent miscarriage. Tissue Antigens 2012; 80(2): 126-35. doi: 10.1111/j.1399-0039.2012. 01884.x.

3. Mosaferi E, Majidi J, Mohammadian M, Babaloo Z, Monfaredan A, Baradaran B. HLA-G expression pattern: reliable assessment for pregnancy outcome 
Mariz H, et al. Comprehensive analysis of polymorphisms in the HLA-G 5'upstream regulatory and 3 'untranslated regions in Brazilian patients with systemic lupus erythematosus. Tissue Antigens 2015; 85(6): 458-65. doi: 10.1111/tan.12545.

11. Abbas A, Tripathi P, Naik S, Agrwal S. Analysis of human leukocyte antigen(HLA)$\mathrm{G}$ polymorphism in normal women and in women with recurrent spontaneous abortions. Eur J Immunogenet 2004; 31(6): 275-8. doi: 10.1111/j.1365-2370.2004.00487.x.

12. Roberta R, Daria B, Silvia B, Enrico F. HLA-G molecules in autoimmune diseases and infections. Front Immunol 2014; 5: 592. doi: 10.3389/fimmu.2014.00592.

13. Le Discorde M, Le Danff C, Moreau P, Rouas-Freiss N, Carosella ED. HLA$\mathrm{G}^{*} 0105 \mathrm{~N}$ null allele encodes functional HLA-G isoforms. Biol Reprod 2005; 73(2): 280-8. doi: 10.1095/biolreprod.104.037986.

14. Simon A, Laufer N, Repeated implantation failure: clinical approach. Fertil Steril 2012; 97(5): 1039-43. doi: 10.1016/j. fertnstert.2012.03.010.

15. Dahl M, Hviid TV. Human leucocyte antigen class $\mathrm{Ib}$ molecules inpregnancy success and early pregnancy loss. Hum Reprod Update 2012; 18(1): 92-109. doi: 10. 1093/humupd/dmr043.

16. Verloes A, Van de Velde H, LeMaoult J, Mateizel I, Cauffman G, Horn PA, et al. HLA-G expression in human embryonic stem cells and preimplantation embryos. J Immunol 2011; 186(4): 2663-71. doi: 10. 4049/jimmunol.1001081.

17. Zidi I, Rizzo R, Bouaziz A, Laaribi AB, Zidi N, Di Luca D, et al. sHLA-G1 and HLA-G5 levels are decreased in Tunisian women with multiple abortion. Hum
Immunol 2016; 77(4): 342-5. doi: 10. 1016/j. humimm.2016.01.019.

18. Nardi Fda S, Slowik R, Wowk PF, da Silva JS, Gelmini GF, Michelon TF, et al. Analysis of HLA-G polymorphisms in couples with implantation failure. Am J Reprod Immunol 2012; 68(6): 507-14. doi: 10.1111/aji.12001.

19. Jassem RM, Shani WS, Loisel DA, Sharief M, Billstrand C, Ober C. HLA-G polymorphisms and soluble HLA-G protein levels in women with recurrent pregnancy loss from Basrah province in Iraq. Hum Immunol 2012; 73(8): 811-7. doi: 10.1016/j. humimm.2012.05.009.

20. Morandi F, Pistoia V. Interactions between HLA-G and HLA-E in physiological and pathological conditions. Front Immunol 2014; 5: 394-9. doi: 10.3389/fimmu.2014. 00394.

21. Ober C, Aldrich CL, Chervoneva I, Billstrand C, Rahimov F, Gray HL, et al. Variation in the HLA-G promoter region influences miscarriage rates. Am J Hum Genet 2003; 72(6): 1425-35.

22. Enghelabifar M, Allafan S, Khayatzadeh J, Shahrokh Abadi Kh, Hasanzadeh Nazarabadi M, Moradi F, et al. Association of the maternal 14-bp insertion/deletion polymorphism in the histocompatibility leukocyte antigen $G$ gene with recurrent implantation failure. Iran J Reprod Med 2014; 12(9): 641-6.

23. Jeong KH, Kim SK, Kang BK, Chung JH, Shin MK, Lee MH. Association between an HLA-G 14 bp insertion/deletion polymorphism and non-segmental vitiligo in the Korean population. Arch Dermatol Res 2014; 306(6): 577-82. doi: 10.1007/s00403014-1459-5. 
24. Barrientos G, Toro A, Moschanskyb P, Cohen M, Garcia MG, Rose B, et al. Leptin promotes HLA-G expression on placental trophoblasts via the MEK/Erk and PI3K signaling pathways. Placenta 2015; 36(4): 419-26. doi: 10.1016/j.placenta.2015.01.006.
25. Rahimi R, Zavaran Hosseini A, Yari F. Null allele frequencies at HLA-G locus in Iranian healthy subjects. Iran J Immunol 2008; 5(4): 207-11. doi: IJIv5i4A3. 